\title{
CALCULATION AND POLICY RESPONSES OF THERMAL POWER CARBON EMISSIONS IN 1995-2015 IN SHAANXI PROVINCE, CHINA
}

\author{
WANG, X. H. - LI, G. \\ School of Humanity and Social Sciences of Xi'an University of Posts and Telecommunications, \\ $X i$ 'an, Shaanxi 710121, China \\ *Corresponding author \\ e-mail:wxh2324@126.com \\ (Received $8^{\text {th }}$ Mar 2019; accepted $21^{\text {st }}$ May 2019)
}

\begin{abstract}
Thermal power industry is a key area of China's energy conservation and emission reduction. Using the national recommendation method, we calculated the carbon emissions data of Shaanxi's thermal power in the 1995-2015 period, and analyzed the response to environmental management policies. The policy response selects energy industry development and environmental governance as the endogenous variables, and uses the methods of co-integration and error correction model to analyze the long-term ensuring future equilibrium and short-term impact mechanism for the three. Based on variance decomposition, this paper refines the contribution of dynamic energy industry development and environmental governance to thermal power carbon emissions. The research shows that the carbon emission of thermal power in Shaanxi province rose from $1891.63 \times 10^{4} \mathrm{t}$ in 1995 to the peak of $11086.14 \times 10^{4} \mathrm{t}$ in 2010 , and then the improvement of energy efficiency has brought a downward trend of carbon emissions. Energy industry development and environmental governance can negatively effect carbon emissions from thermal power plants. In the long run, carbon emissions from thermal power plants can be gradually reduced. The contribution of the two variables is about $5 \%$ and $6 \%$ respectively, which has great room for improvement.
\end{abstract}

Keywords: energy industry development, environmental governance, call mechanism, efficiency improvement, pollution reduction

\section{Introduction}

Using the heat generated from coal and other combustion-based methods to produce electricity, thermal power generation is the main source of power in China and one of the main $\mathrm{CO} 2$ emission sources. At present, the thermal power industry has become a key area of national energy conservation and emission reduction. China's thermal power enterprises are mainly concentrated in Jiangsu, Shandong, Shaanxi and several other, and Shaanxi in 2010 became the first batch of the country's low carbon experimental development province, therefore, the measurement of thermal power carbon emission in Shaanxi province can provide effective data basis for the management of regional energy saving and emission reduction (Nas and TalebianKiakalaieh, 2017; Majumder et al., 2019).

In the current research, the calculation of carbon emission of thermal power is mainly expressed as "energy consumption method", that is to sum up energy consumption, and calculate carbon emission volume in combination with various energy carbon emission factors (Licht et al., 2018; Pazand and Hezarkhani, 2018). "Energy consumption law" can be used to estimate the carbon emissions of the industry better, but this method is limited to static research, neglects the carbon emission in the process of power transmission from the thermal power industry and the process of desulfurization, which eventually leads to the leakage calculation of carbon emissions 
(Bergthorson, 2018; Joseph et al., 2019). Therefore, it is necessary to improve the carbon emission research systematically and dynamically.

In 2013, the State Development and Reform Commission of China issued the Guidelines for the Accounting Methods and Reporting of Greenhouse Gas Emissions by China's Power Generation Enterprises (Trial Implementation) to determine the emission standards of air pollutants in thermal power plants. Based on the national development and Reform Commission's guidance method, this paper calculates the thermal power carbon emission data in Shaanxi province in 1995-2015, probes the response relationship of relevant policies to thermal power carbon emissions, and analyzes its long-term equilibrium and short-term impact mechanism to provide reference for future environmental management policy formulation (Ma et al., 2017; Sufiyan et al., 2018).

Shaanxi, also known as Qin, is located between the eastern longitude $105^{\circ} 29^{\prime}-$ $111^{\circ} 15^{\prime}$ and northern latitude $31^{\circ} 42^{\prime}-30^{\circ} 35^{\prime}$. It has jurisdiction over 10 prefecture-level cities, such as Xi'an, Xianyang, Yan'an and Hanzhong, and is an important hub connecting eastern, central, northwestern and southwestern China. The topography of Shaanxi includes mountains, highlands, plains and basins (Fig. 1). The total area is 205 thousand and $800 \mathrm{~km}^{2}$. The forest coverage rate was $43.06 \%$. The Yellow River basin covers an area of 133 thousand and $300 \mathrm{~km}^{2}$, and the Yangtze River Basin has an area of 72 thousand and $300 \mathrm{~km}^{2}$ (Velea et al., 2009; Rajput et al., 2019). The annual average temperature of the province is 13.6 centigrade; the annual precipitation is $598.1 \mathrm{~mm}$.

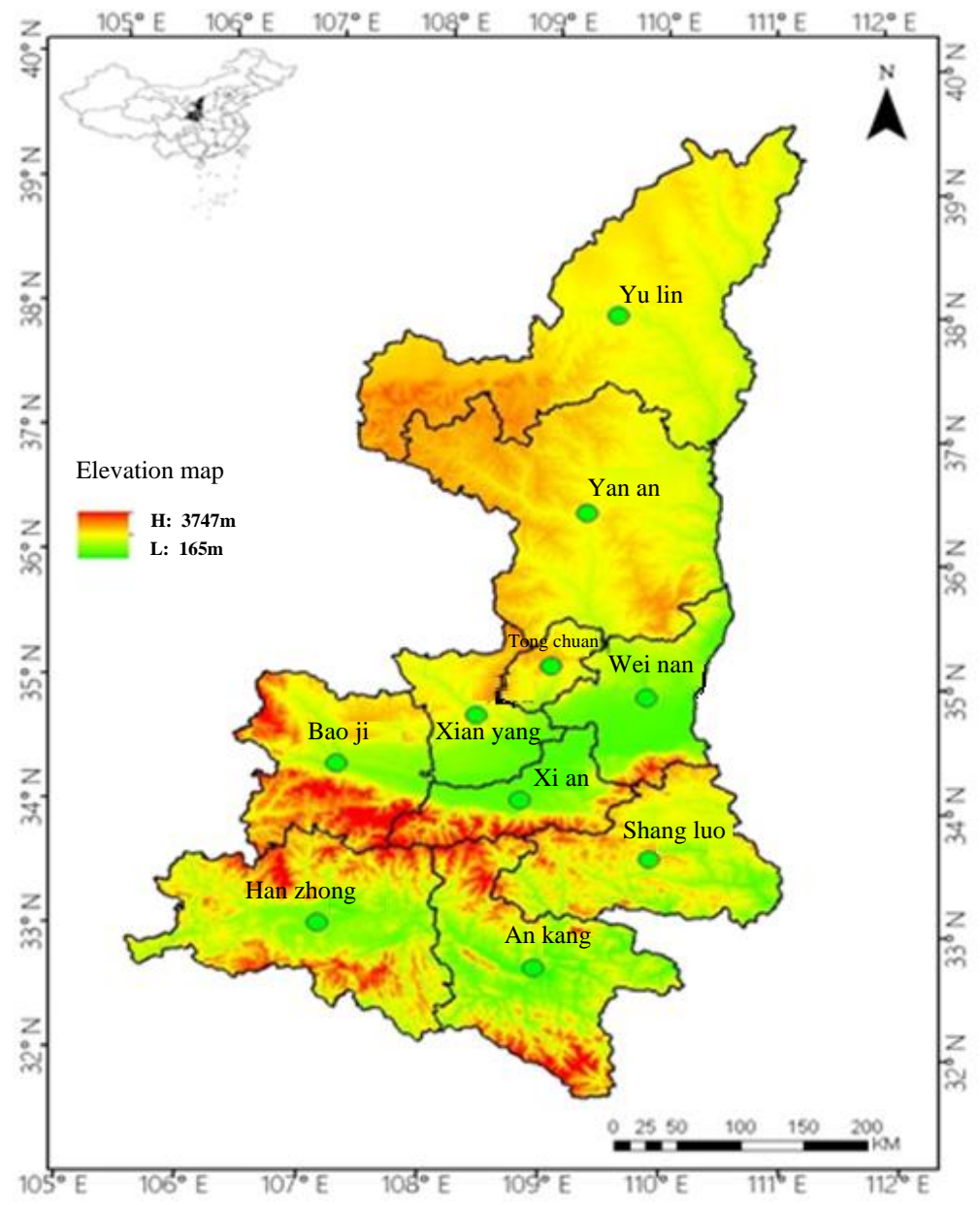

Figure 1. Elevation map of the Shaanxi Province 


\section{Methodology}

\section{Calculation of carbon emission in thermal power}

The Accounting Methods and Reporting Guidelines for Greenhouse Gas Emissions from China's power generation enterprises (Trial Implementation) regulates that the total amount of greenhouse gas emissions from power generation enterprises is equal to the emission of fossil fuel combustion in the boundary of the enterprise, the discharge of the desulfurization process and the emissions generated by the net purchase and use of electricity. Among them,

$$
\begin{aligned}
& E_{\text {energy consumption }}=\sum A D_{\mathrm{i}} \times E F_{\mathrm{i}} \\
& E_{\text {desulfurization process }}=\sum C A L \times E F \\
& E_{\text {electricity purchase }}=\sum A D \times E F
\end{aligned}
$$

In Equations 1, 2 and 3, $\mathrm{AD}_{\mathrm{i}}$ is the level of $\mathrm{i}$ energy activity, which is expressed in the calorific value (Atimtay, 2003; Kumar et al., 2017; Kumar, 2018), $\mathrm{EF}_{\mathrm{i}}$ is the i emission factor; CAL is the consumption of carbonate in the process of desulfurization; EF is the emission factor of carbonate in the desulfurizer. Based on the real situation of thermal power generation in China, the desulfurizer is limestone, its carbonate content is $90 \%$ by default, and the carbon emission factor is 0.44 .2 thousand and 700 tons of limestone is consumed at 100 million $\mathrm{kW}$ h of power generation. AD is the purchase of electricity, and error factor $(\mathrm{EF})$ is the emission factor.

\section{Vector autoregression and vector error correction model construction}

\section{(1) Vector autoregressive model and error correction model}

Vector autoregressive models are often used to predict interconnected time series systems and to analyze the dynamic effects of random disturbances on variable systems. The expression is:

$$
Y_{t}=A_{1} Y_{t-1}+A_{2} Y_{t-2}+\cdots A_{p} Y_{t-p}+B X_{t}+\varepsilon_{t}, \quad t=1,2, \cdots T
$$

Among them, $\mathrm{Y}_{\mathrm{t}}$ is a vector of $\mathrm{k}$ endogenous variable; $\mathrm{X}_{\mathrm{t}}$ is a $\mathrm{d}$ dimension exogenous variable vector; $\mathrm{p}$ is a lag order; $\mathrm{T}$ is a sample number; $\varepsilon_{t}$ is a $\mathrm{k}$ dimension error vector, $A_{1}, A_{2} A_{p}, B$ is an estimated coefficient matrix.

However, the defect of vector autoregressive model is that it cannot describe the relationship between synchronous variables, and the error correction model can deal with this problem better.

$$
\Delta Y_{\mathrm{t}}=\alpha E C M_{t-1}+\sum_{i=1}^{p-1} \Gamma_{i} \Delta Y_{t-i}+\varepsilon_{t}
$$

Among them, $E C M_{t-1}$ is the error correction term, $\alpha$ is the adjustment coefficient, and the influence coefficient of $\Gamma_{i}$ is $\Delta Y_{t-i}$ 's short term fluctuation on $\Delta Y_{\mathrm{t}}$. 


\section{(2) Selection and treatment of index}

In the field of environmental governance, energy industry technology upgrading and industrial pollution control are the main strategies for energy conservation and emission reduction (Valiani et al., 2016; Jamil et al., 2018). As the electricity belongs to the energy industry, in order to better reflect the corresponding management, the energy industry investment (EIS) and the industrial pollution control investment (IPS) are selected to represent the status quo of the development of energy industry and the status of environmental governance respectively, and the endogenous variables of the thermal power carbon emission (CES) model are constructed (Reddy and Momoh, 2016; Ali et al., 2018).

According to the selection index, Equation $4: Y=\left[\begin{array}{l}C E S \\ E I S \\ I P S\end{array}\right], \quad X=0$. In order to reduce the large fluctuation of data, the natural logarithms of CES, EIS and IPS sequences are taken respectively. The $X, Y, t$ value substitution $(E q .4)$ can be obtained:

$$
\begin{aligned}
& {\left[\begin{array}{l}
\text { LCES } \\
\text { LEIS } \\
\text { LIPS }
\end{array}\right]_{t}=\left[\begin{array}{l}
a_{0} \\
a_{1} \\
a_{3}
\end{array}\right]+\left[\begin{array}{lll}
b_{11} & b_{12} & b_{13} \\
b_{21} & b_{22} & b_{23} \\
b_{31} & b_{32} & b_{33}
\end{array}\right]\left[\begin{array}{l}
\text { LCES } \\
\text { LEIS } \\
\text { LIPS }
\end{array}\right]_{t-1}} \\
& +\left[\begin{array}{lll}
c_{11} & c_{12} & c_{13} \\
c_{21} & c_{22} & c_{23} \\
c_{31} & c_{32} & c_{33}
\end{array}\right]\left[\begin{array}{l}
\text { LCES } \\
\text { LEIS } \\
\text { LIPS }
\end{array}\right]_{t-2}+\left[\begin{array}{l}
\hat{\varepsilon}_{0} \\
\hat{\varepsilon}_{1} \\
\hat{\varepsilon}_{2}
\end{array}\right]_{t}
\end{aligned}
$$

\section{Results, analysis and discussion}

The data of thermal power consumption, the average low calorific value of energy and electricity purchased are derived from the 《Shaanxi statistical yearbook $\rangle$. The unit calorific value carbon content data comes from the provincial carbon emission accounting guide and Intergovernmental Panel on Climate Change (IPCC) standard. Some energy data and the average emission factor of regional power grid are derived from "The guide to China's carbon emissions accounting". Among them, the average emission factor of the northwest regional power grid is $0.977 \mathrm{~kg} / \mathrm{KW} \mathrm{h}$, Over the years, the investment in Shaanxi's energy industry and investment in industrial pollution control came from the National Bureau of statistics of China (Salem, 2018; Hossain et al., 2019).

\section{Empirical results and analysis}

\section{(1) Carbon emission of thermal power in Shaanxi}

The results of thermal power carbon emission calculation in Shaanxi Province from 1995 to 2015 are in Table 1. The carbon emission of thermal power in Shaanxi Province has been increasing since 1995 until the turning point of 2010. The emission reached its peak of $11086.14 \times 10^{4} \mathrm{t}$ in 2010 , which is due to the $190.52 \times 10^{8} \mathrm{KW} \mathrm{h}$ increase of 
the thermal power generation in 2010 compared with the previous year. The amount of raw coal used for thermal power generation increased from3949.22 $\times 10^{4} \mathrm{t}$ in 2009 to $4850 \times 10^{4} \mathrm{t}$, and then dropped to $4107.56 \times 10^{4} \mathrm{t}$ in 2011 (Boutabba and Lardic, 2016; Shrestha and Baral, 2018).

Table 1. The carbon emission of thermal power generation in Shaanxi Province (unit: $10^{4} t$ )

\begin{tabular}{c|c|c|c|c|c}
\hline Time & Emission value & Time & Emission value & Time & Emission value \\
\hline 1995 & 1891.63 & 2002 & 3312.53 & 2009 & 8177.14 \\
1996 & 2177.56 & 2003 & 4350.98 & 2010 & 11086.14 \\
1997 & 2471.41 & 2004 & 5148.33 & 2011 & 9206.80 \\
1998 & 2589.26 & 2005 & 5014.09 & 2012 & 9428.29 \\
1999 & 2701.68 & 2006 & 5805.92 & 2013 & 9445.80 \\
2000 & 2737.83 & 2007 & 6296.26 & 2014 & 9502.33 \\
2001 & 2902.70 & 2008 & 7134.40 & 2015 & 9533.27 \\
\hline
\end{tabular}

At the same time, according to the composition of Shaanxi's thermal power carbon emissions (Fig. 2), we can also see in the purchase of electric power plate, Shaanxi's purchase of electricity carbon emissions also reached a maximum of $1608.92 \times 10^{4} \mathrm{t}$ in 2010 (Moon and Seo, 2016). Since 2011, the purchase of electricity has been blank, which has led to the historical peak of Shaanxi's thermal power carbon emissions in 2010 .

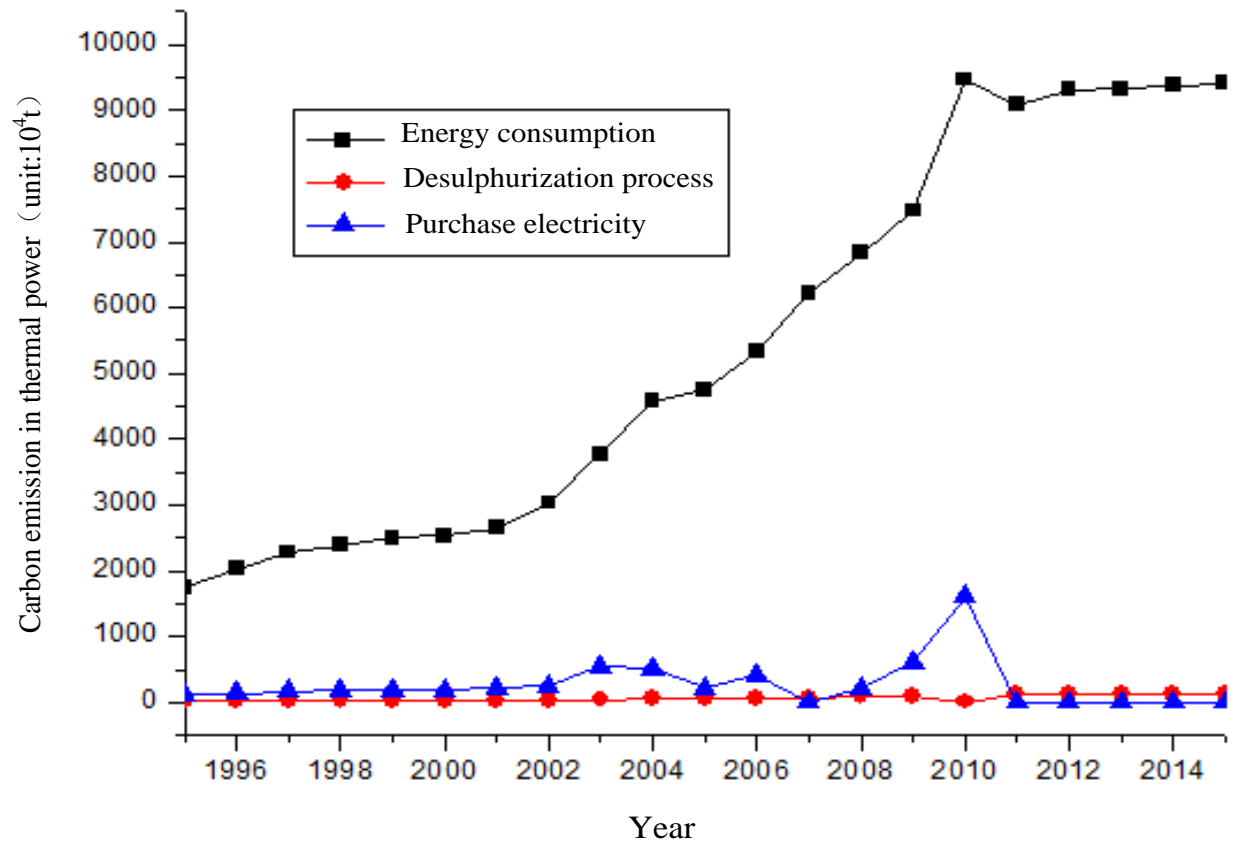

Figure 2. Carbon emission from Shaanxi Province

In the comparison of three components of thermal power carbon emissions, energy consumption becomes the key source of carbon emissions again (Moon and Shin, 2017). The total amount of carbon emissions in the desulfurization process is the lowest, 
and the purchase of electricity has been kept low before 2009. In 2010, the purchase of electricity in Shaanxi province increased sharply, followed by a state of " 0 " in the following years.

For the fluctuation of carbon emission in Shaanxi thermal power industry, the reason is the policy changes (Deleidi, 2017). In the plan of "11th Five-Year" from 2005 to 2010, carbon emission reduction in Shaanxi province is to by the means of "optimize the development of thermal power enterprises", the main measures are to actively improve the power generation technology and to the reduce the coal consumption during the process of power generation. During that period, thermal power generation or province is the main form of power generation (Kalshian, 2016). In the period of "12th Five-Year", the plan clearly proposes to vigorously develop hydropower, wind power and solar power, and carries out the project of "gasification Shaanxi" in an all-round way. So the standard coal consumption per unit energy consumption and thermal power supply were reduced by $16 \%$ and $13 \%$ on the basis of 2010 . In 2011-2015, thermal power generation continued to increase, but carbon emission is under control, indicating that thermal power energy efficiency has been improved. At the same time, the improvement of clean energy production capacity, such as hydropower, has also contributed to the efficiency of carbon emission reduction.

Taking hydroelectric power as an example, the generation of hydropower in Shaanxi Province increased five times from $25.43 \times 10^{8} \mathrm{KW}^{*} \mathrm{~h}$ in 1995 to $112.98 \times 10^{8} \mathrm{KW}^{\circ} \mathrm{h}$ in 2014. The generation of wind power in 2015 was $28 \times 10^{8} \mathrm{KW}^{\circ} \mathrm{h}$. Average utilization hours of power generation in 2015 were $281 \mathrm{~h}$ less than the previous year, $499 \mathrm{~h}$ for hydropower, $210 \mathrm{~h}$ for wind power and $354 \mathrm{~h}$ less for thermal power (Bloom et al., 2016). Therefore, the improvement of energy efficiency and the rapid construction of clean energy such as water conservancy and wind power have promoted the low-carbon development of Shaanxi electric power industry.

In a comprehensive view, although the power generation capacity of hydropower and wind power is increasing annually, the proportion of the total amount of electricity generated by these powers is very small compared with the amount of thermal power generated. The thermal power occupies $90 \%$ of the power generation, so currently the thermal power is main the power production in Shaanxi. In 2015, the total installed capacity of China's power generation was $149000 \times 10^{4} \mathrm{KW}$, and the total installed capacity of thermal power was $101150 \times 10^{4} \mathrm{KW}$. It is predicted that the total installed capacity of thermal power generation in China will increase to $200000 \times 10^{4} \mathrm{KW}$ and $380000 \times 10^{4} \mathrm{KW}$ by 2020 and 2050 , among which thermal power is also predicted to reach $124650 \times 10^{4} \mathrm{KW}$ and $154700 \times 10^{4} \mathrm{KW}$ in each year. The increase of the capacity cannot be separated from the capital investment of the country, so in the environment management, the investment in the energy industry and the treatment of industrial pollution will play key roles in the carbon emissions in the related industries (Taylor, 2009).

\section{Model verification and analysis}

\section{(1) Model parameter estimation}

The stability of time series data is the precondition to ensure the validity of the model. Automatic Direction Finder (ADF) method is used to test the stability of data by unit root (Table 2). In the selection of lag order, the optimal lag period is determined to be 2 order based on Chichi information criterion (AIC) and Schwartz criterion (SC). 
Table 2. ADF stability test

\begin{tabular}{|c|c|c|c|c|c|c|}
\hline Variable & $\begin{array}{c}\text { ADF } \\
\text { statistics }\end{array}$ & $\begin{array}{l}1 \% \text { critical } \\
\text { value }\end{array}$ & $\begin{array}{l}5 \% \text { critical } \\
\text { value }\end{array}$ & $\begin{array}{l}10 \% \text { critical } \\
\text { value }\end{array}$ & $P$ value & Conclusion \\
\hline$L C E$ & -0.636 & -2.700 & -1.961 & -1.607 & 0.2361 & Unstable \\
\hline$\triangle L C E$ & -2.910 & -2.700 & -1.961 & -1.607 & 0.0097 & Stable \\
\hline$L E I_{i}$ & -1.602 & -2.700 & -1.961 & -1.607 & 0.1088 & Unstable \\
\hline$\triangle L E l$ & -3.692 & -2.700 & -1.961 & -1.607 & 0.0018 & Stable \\
\hline$L I P$ & -0.9613 & -2.700 & -1.961 & -1.607 & 0.2236 & Unstable \\
\hline$\triangle L I P$ & -4.299 & -2.700 & -1.961 & -1.607 & 0.0005 & Stable \\
\hline
\end{tabular}

From Table 2 we can see that LCES, LEIS and LIPS of the ADF statistics are greater than $10 \%$, which contain unit roots and non-stationary sequences. But the test values of the first difference are less than $1 \%$ of the critical value, the difference sequence does not contain the unit root, so the difference sequence is stable, and the data series conforms to the requirement of the construction model. The statistical software EViews7.2 is used to build the model. The result of operation data is substituted (Eq. 6$)$, and the vector auto regression model is:

$$
\begin{aligned}
& {\left[\begin{array}{l}
\text { LCES } \\
\text { LEIS } \\
\text { LIPS }
\end{array}\right]_{t}=\left[\begin{array}{l}
3.047 \\
-4.290 \\
0.990
\end{array}\right]+\left[\begin{array}{lll}
0.596 & 0.319 & 0.109 \\
0.946 & 0.819 & -0.152 \\
0.813 & 0244 & 0.167
\end{array}\right]\left[\begin{array}{l}
\text { LCES } \\
\text { LEIS } \\
\text { LIPS }
\end{array}\right]_{t-1}} \\
& +\left[\begin{array}{ccc}
-0.216 & -0.200 & 0.033 \\
-0.117 & -0.163 & 0.095 \\
-0.410 & 0.059 & 0.301
\end{array}\right]\left[\begin{array}{l}
L C E S \\
L E I S \\
L I P S
\end{array}\right]_{t-2}+\left[\begin{array}{l}
\hat{\varepsilon}_{0} \\
\hat{\varepsilon}_{1} \\
\hat{\varepsilon}_{2}
\end{array}\right]_{t}
\end{aligned}
$$

The model ( $E q .7)$ is a variable system of carbon emissions, energy industry development and environmental governance of thermal power plants in Shaanxi. The AR root test of the model is based on the principle that the reciprocal of the model with all the characteristic roots of the model is less than 1. From Figure 3 we can find that the model has 6 characteristic roots, and the reciprocal of all the eigenvalues of the model is in the unit circle, so the model is stable.

Meanwhile, according to the residual synchronization correlation matrix between variables, we can test the variables have mutual influence, and the correlation coefficients of LCES and LEIS, LIPS are 0.6071 and 0.4259 respectively (Bloch et al., 2012; Rojamary and Uma, 2017). Therefore, in order to explore the response mechanism between the energy industry development, environmental governance and thermal power carbon emission, we need to further cointegration test of the residual sequence of model ( $E q .7)$, in order to understand whether there is a long-term equilibrium relationship between the three variables. The real economic data are often caused by the "unbalanced process", the long-term equilibrium relationship can not reflect the short-term change. So we need to build vector error correction model to analyze what kind of short-term effects the variables will have if they deviate from equilibrium relations. 


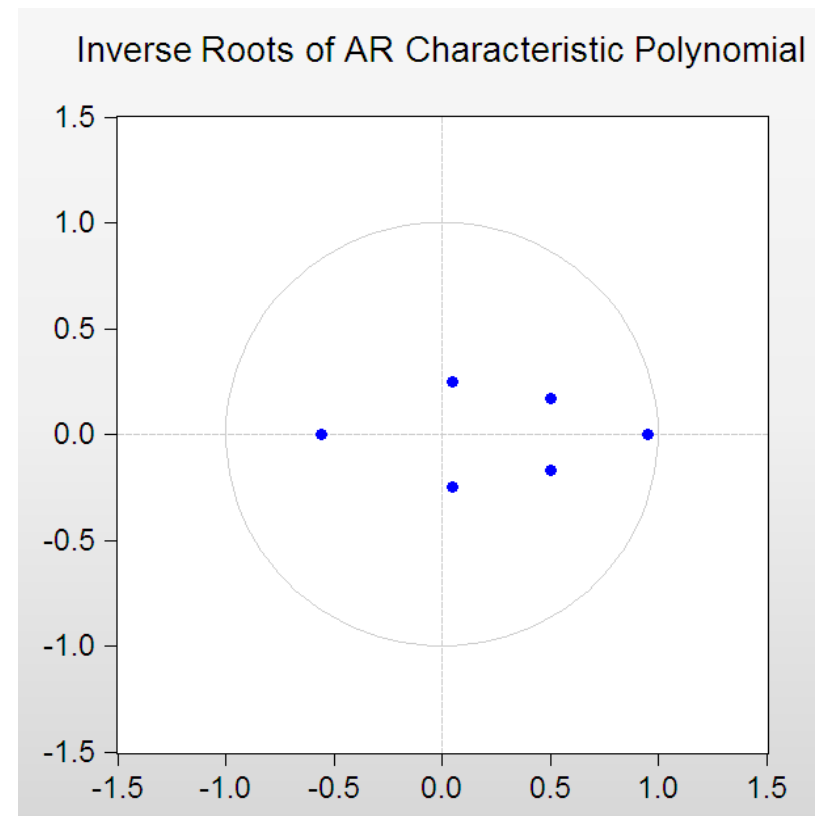

Figure 3. Unit circle and characteristic root

\section{(2) Response mechanism of thermal power carbon emissions}

Pseudo regression is likely to occur in nonstationary sequences. Johansen cointegration test is used to verify multiple variables, and whether there is a stable relationship between variables (Table 3 ).

Table 3. Johansen co-integration test

\begin{tabular}{c|c|c|c|c|c}
\hline Number of equations & Characteristic value & Trace statistics & 5\% critical value & P value & Conclusion \\
\hline 0 & 0.8225 & 35.9189 & 29.7971 & 0.0087 & Refuse \\
Up to 1 & 0.3044 & 6.53111 & 15.4847 & 0.6327 & Accept \\
Up to 2 & 0.0211 & 0.36107 & 3.84147 & 0.5479 & Accept \\
\hline
\end{tabular}

Table 3 shows a co-integration relationship at the 5\% level, indicating a long-term equilibrium between energy industry development and environmental governance, and thermal carbon emissions. The cointegration equation is as follows:

$$
\begin{array}{rc}
L C E S=0.3470 L E I S-0.1225 L I P S \\
\text { Standard deviation }=(0.0249) & (0.0252)
\end{array}
$$

According to cointegration equation, the elastic coefficient of energy industry development to thermal power carbon emission is 0.3470 , that is, the investment of energy industry increases by $1 \%$, the carbon emission of thermal power increases by about $0.35 \%$, and the treatment of environmental pollution is negative (Oluleye et al., 2018 ; Li et al., 2013). It shows that the investment of industrial pollution control can effectively reduce the carbon emissions of thermal power enterprises. At the same time, the error correction term can be constructed based on the cointegration equation (Eq. 8) and the error correction model is established (Table 4). 
Table 4. Error correction model coefficient vector statistics

\begin{tabular}{c|c|c|c}
\hline Error correction & D(LCES) & D(LEIS) & D(IPS) \\
\hline CointEq1 & -0.4445 & 2.0404 & -0.0995 \\
D((LCES)-1 $)$ & 0.3750 & -0.7096 & 1.6479 \\
D((LCES)-2) & 0.1972 & -0.8650 & 0.4596 \\
D((LEIS) -1$)$ & 0.0163 & 0.3469 & -0.0187 \\
D((LEIS) -2$)$ & -0.1912 & 0.0351 & 0.4608 \\
D((IPS) -1$)$ & -0.0544 & -0.0020 & -0.8466 \\
D((IPS) -2$)$ & -0.1293 & -0.0729 & -0.5882 \\
C & 2.9200 & 0.6578 & 39.0031 \\
\hline
\end{tabular}

A vector error correction model (Eq. 9) is established from Table 4:

$$
\begin{aligned}
& {\left[\begin{array}{l}
D(\text { LCES }) \\
D(\text { LEIS }) \\
D(\text { LIPS })
\end{array}\right]=\left[\begin{array}{l}
2.920 \\
0.658 \\
39.003
\end{array}\right]+\left[\begin{array}{ll}
0.375 & 0.016-0.054 \\
-0.7100 .347-0.002 \\
1.648 & -0.019-0.847
\end{array}\right]\left[\begin{array}{l}
D(L C E S) \\
D(\text { LEIS }) \\
D(\text { LIPS })
\end{array}\right]_{t-1}} \\
& +\left[\begin{array}{ccc}
0.197 & -0.191 & 0.129 \\
-0.865 & 0.035 & -0.073 \\
0.460 & 0.461 & -0.588
\end{array}\right]\left[\begin{array}{l}
D(L C E S) \\
D(\text { LEIS }) \\
D(L I P S)
\end{array}\right]_{t-2} \\
& +\left[\begin{array}{l}
-0.445 \\
2.040 \\
-0.100
\end{array}\right]\left(\text { LCES }_{t}-0.347 \text { LEIS }+0.123 \text { LIPS }\right)+\hat{\varepsilon}_{t}
\end{aligned}
$$

Equation 9 the error correction model consists of two parts: one is the short-term effect of itself and other variables, and the other is the effect of deviating from the longterm equilibrium relationship. Among them, $-0.445,2.040$ and -0.100 respectively indicate that the carbon emission of thermal power, the development of energy industry and the environmental governance will deviate in the speed and direction from the longterm cointegration. Judging from the absolute value, the development of the energy industry has the fastest speed (Kang et al., 2018; Jiang et al., 2018; Raja, 2017). From the view of direction, the investment of thermal power carbon emissions and the environmental governance have a negative adjustment effect on the cointegration relationship.

Based on the research object of this paper, the error correction model of thermal power carbon emission is emphatically analyzed. Its determinant is:

$$
\begin{aligned}
& D(\text { LCES })=-0.4445 *(\operatorname{LCES}(-1)-0.3470 * \operatorname{LEIS}(-1)+0.1225 * \operatorname{LIPS}(-1)-5.1705) \\
& +0.3750 * D(\operatorname{LCES}(-1))+0.1972 * D(\operatorname{LCES}(-2))+0.01630 * D(\operatorname{LEIS}(-1)) \\
& -0.1912 * D(\operatorname{LEIS}(-2))-0.0544 * D(\operatorname{LIPS}(-1))-0.1294 * D(\operatorname{LIPS}(-2))+2.9200
\end{aligned}
$$

From Equation 10, we can judge energy industry development and environmental governance can negatively adjust carbon emissions from thermal power plants. Investment in energy industry construction can improve the level of technological 
productivity, and industrial pollution investment directly promotes the control of various pollution sources. IPS lag difference coefficient is - 0.0544 and - 0.1294 respectively, indicating that short-term fluctuations in environmental management can reduce the amount of carbon emissions from thermal power plants. The impact of EIS on carbon emissions of thermal power is not stable, but from the view of impact coefficient, it can inhibit carbon emissions.

\section{(3) Analysis of contribution}

Co-integration analysis and error correction model estimate the long term equilibrium and short-term impact mechanism between the development of energy industry and environmental governance and the carbon emissions in thermal power plants from a static point of view. The impulse response function can help us understand the dynamic characteristics of the development of the energy industry, environmental governance and the response of thermal power to carbon emissions better.

Figure 4 shows the results of impulse response of carbon emission from thermal power to the energy industry development and environmental governance respectively. The horizontal axis represents the lag period of impact, the vertical axis represents the amount of carbon emissions, the solid line represents the impulse response function, and the dotted line represents the deviation band of positive and negative double standard deviation. According to Figure 4, the response of thermal power carbon emissions to energy industry development and environmental governance are similar, reaching the highest value in the second phase. Energy industry investment keeps declining from the third phase until the sixth phase to reach the stability, showing the trend of convergence. Environmental governance has a response fluctuation in the third and fourth periods, and tends to be stable and convergent after the fifth phase. It shows that the development of energy industry and environmental control in Shaanxi Province are effective in the long run, and the carbon emission of thermal power can be slowed down step by step. Variance decomposition is used to analyze the contribution of each structural shock to the change of thermal power carbon emissions (Table 5), so as to evaluate the contribution of different variables.
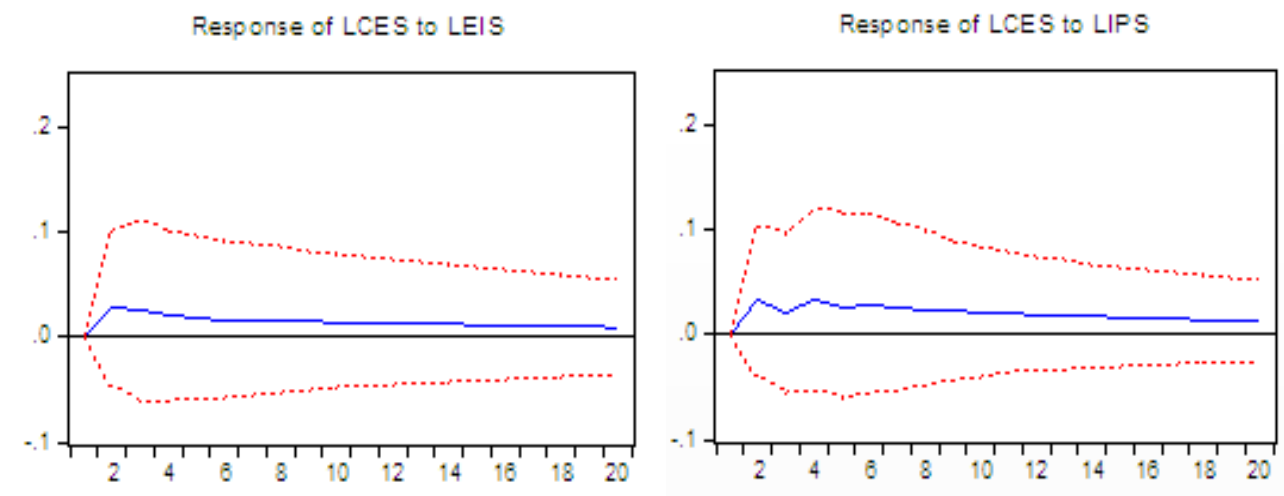

Figure 4. Impulse response of thermal power carbon emissions to energy industry development and environmental governance

As can be seen from Table 5, the interference response of thermal power carbon emission itself shows the trend of decreasing, and the contribution degree of energy 
industry development and environmental governance is increasing gradually in the ninth phase. From the second to the fourth, the contribution of the energy industry is higher than the environmental governance, and the improving of energy efficiency can reduce the carbon emissions rapidly. However, due to the phase nature of the technology renewal, the contribution of the energy industry is slowed down from the fifth stage; the contribution of the two is $5 \%$ and $6 \%$ respectively in the 20 phase. It shows that the development of energy industry and the intensity of environmental pollution control have certain explanatory to the fluctuation of carbon emissions from thermal power plants, which have a greater room for improvement.

Table 5. Variance decomposition

\begin{tabular}{c|c|c|c}
\hline \multirow{2}{*}{ Phases } & \multicolumn{3}{|c}{ Variance contribution } \\
\cline { 2 - 4 } & LCES & LEIS & LIPS \\
\hline 1 & 100.0000 & 0.0000 & 0.0000 \\
2 & 94.5204 & 2.7914 & 2.6882 \\
3 & 93.4209 & 3.7777 & 2.8015 \\
4 & 92.0112 & 4.1107 & 3.8780 \\
5 & 91.4399 & 4.2839 & 4.2762 \\
6 & 90.8427 & 4.4295 & 4.7279 \\
7 & 90.4889 & 4.5483 & 4.9628 \\
8 & 90.1787 & 4.6484 & 5.1729 \\
9 & 89.9582 & 4.7307 & 5.3111 \\
10 & 89.7720 & 4.7995 & 5.4284 \\
15 & 89.2392 & 5.0082 & 5.7524 \\
20 & 88.9946 & 5.1045 & 5.9009 \\
\hline
\end{tabular}

\section{Conclusions}

Economic development depends on the drive of power and energy. Based on the estimated carbon emission values of thermal power in Shaanxi province in 1995-2015, combined with the investment of energy industry and environment governance, the VCE model is constructed to explore the long-term equilibrium and short-term fluctuation response mechanism between the three variables. The following conclusions are drawn:

(1) Shaanxi thermal power carbon emission keeps rising from 1995 until 2010. Because of the drastically increase of the amount of raw coal used in thermal power in 2010, thermal power carbon emissions reaches the peak in the recent 20 years. The development of hydropower, wind power, solar power generation and the reduction of standard coal consumption have promoted the low carbon industry in Shaanxi province.

(2) There is a long-term co-integration relationship between energy industry development, environmental governance and thermal power carbon emissions. Energy industry development and environmental governance can negatively adjust thermal power carbon emissions.

(3) In terms of contribution rate, the contribution rate of energy industry development and environmental governance has gradually increased. The contribution rate of industrial pollution control investment is slightly higher than that of energy industry investment. Therefore, in the future development of Shaanxi thermal power 
industry, we should adjust the energy structure, make full use of non-fossil energy, and actively optimize and upgrade of industrial structure.

(4) Increase investment in wind power and hydropower to reduce environmental pollution caused by thermal power generation.

Generally speaking, most scholars use the energy consumption method to calculate the carbon emission of thermal power, that is, the energy consumption of thermal power is multiplied by the energy carbon emission factor. On the basis of "energy consumption", this paper takes the desulfurization process and the carbon emission of power transmission into consideration. So it is relatively comprehensive. Industrial pollutants include waste water, waste gas, solid waste, noise and so on, due to the lack of part of the waste gas treatment data, this paper uses the total investment of industrial pollution control to construct the error correction model. Since the average proportion of investment in waste gas control in 2004-2015 was 49.72\%, in 2013 and 2014 the annual waste gas investment accounted for $77 \%$, the total investment in environment governance can represent the objective impact of waste gas treatment. Meanwhile, the electricity consumption of specific industries is an important basis for carbon emission reduction of thermal power plants. Based on the analysis of industrial macro data, this paper will further explore the main emission reduction paths of thermal power carbon emissions.

Acknowledgements. This paper is sponsored by The National Natural Science Foundation of China (41501093); and Sponsored by Social Science Planning Project of Shaanxi Province (2016R022).

\section{REFERENCES}

[1] Ali, W., Nasir, M. S., Nasir, A., Rashid, H., Ayub, I., Gillani, S. H., Latif, M. J. (2018): Assessment of carbon footprints in terms of $\mathrm{CO}_{2}$ of diesel generator, Pakistan. - Earth Sciences Pakistan 2(1): 15-17.

[2] Atimtay, A. T. (2003): A global outlook to the carbon dioxide emissions in the world and emission factors of the thermal power plants in Turkey. - Water Air \& Soil Pollution Focus 3(5-6): 335-345.

[3] Bergthorson, J. M. (2018): Recyclable metal fuels for clean and compact zero-carbon power. - Progress in Energy \& Combustion Science 68: 169-196.

[4] Bloch, H., Rafiq, S., Salim, R. (2012): Coal consumption $\mathrm{CO}_{2}$, emission and economic growth in China: empirical evidence and policy responses. - Energy Economics 34(2): 518-528.

[5] Bloom, D. E., Chatterji, S., Kowal, P. (2015): Macroeconomic implications of population ageing and selected policy responses. - Lancet 385(9968): 649.

[6] Boutabba, M. A., Lardic, S. (2016): EU emissions trading scheme, competitiveness and carbon leakage: new evidence from cement and steel industries. - Annals of Operations Research 255(1): 47-61.

[7] Deleidi, M. (2017): Post Keynesian endogenous money theory: a theoretical and empirical investigation of the credit demand schedule. - Journal of Post Keynesian Economics (2): 1-25.

[8] Hossain, M. S., Karlson, M., Neset, T. S. (2019): Application of gis for cyclone vulnerability analysis of Bangladesh. - Earth Sciences Malaysia 3(1): 25-34.

[9] Jamil, F., Arshad, R., Ali, M. A. (2018): Design, fabrication and evaluation of rotary hotair dryer for the value addition of fruit waste. - Earth Sciences Pakistan 2(2): 07-11. 
[10] Jiang, S., Lian, M., Lu, C., Gu, Q., Ruan, S., Xie, X. (2018): Ensemble prediction algorithm of anomaly monitoring based on big data analysis platform of open-pit mine slope. - Complexity 2018.

[11] Joseph, O. T., Adeoti, O. O., Olufemi, A. A. (2019): Study of the phytodiversity along Antorun Reservoir, near Ogbomoso, Nigeria. - Environment \& Ecosystem Science 3(1): $1-12$.

[12] Kalshian, R. (2016): Introduction: Energy versus emissions: the big challenge of the new millennium. - Journal of International Consumer Marketing 26(1): 58-74.

[13] Kang, L., Du, H. L., Zhang, H., Ma, W. L. (2018): Systematic research on the application of steel slag resources under the background of big data. - Complexity 2018. https://doi.org/10.1155/2018/6703908.

[14] Kumar, M., Mao, Y., Wang, Y., Qiu, T., Chenggen, Y., Zhang, W. (2017): Fuzzy theoretic approach to signals and systems: static systems. - Information Sciences 418: 668-702.

[15] Kumar, R. (2018): Comparison of instruction scheduling and register allocation for MIPS and HPL-PD architecture for exploitation of instruction level parallelism. - Engineering Heritage Journal 2(2): 04-08.

[16] Li, G., Chen, M. (2013) Intertwined phenomenon of a kind of dynamical systems. Advances in Difference Equations 2013(1): 265.

[17] Licht, S., Wu, H. J., Hettige, C. (2018): STEP cement: solar thermal electrochemical production of $\mathrm{CaO}$ without $\mathrm{CO}_{2}$ emission. - Chemical Communications 48(48): 60196021.

[18] Ma, X. J., Wang, Y., Wang, C. (2017): Low-carbon development of China's thermal power industry based on an international comparison: review, analysis and forecast. Renewable \& Sustainable Energy Reviews 80: 942-970.

[19] Majumder, S. C., Islam, K., Hossain, M. M. (2019): State of research on carbon sequestration in Bangladesh: a comprehensive review. - Geology, Ecology, and Landscapes 3(1): 29-36.

[20] Moon, G. H., Seo, J. Y. (2017): Dynamic mechanism between economic shocks and adjustments to loan portfolio weight: evidence from South Korean banks. - Journal of the Asia Pacific Economy 4: 1-19.

[21] Moon, T., Shin, D. H. (2017): Forecasting model of construction cost index based on VECM with search query. - KSCE Journal of Civil Engineering 11: 1-9.

[22] Nas, A., Talebian-Kiakalaieh, A. (2017): Reduction of $\mathrm{CO}_{2}$ emission by INCAM model in Malaysia biomass power plants during the year 2016. - Waste Manage 73: 256-264.

[23] Oluleye, G., Allison, J., Kelly, N. (2018): An optimisation study on integrating and incentivising thermal energy storage (TES) in a dwelling energy system. - Energies 11(5): 1095.

[24] Pazand, K., Hezarkhani, A. (2018): Predictive Cu porphyry potential mapping using fuzzy modelling in Ahar-Arasbaran zone, Iran. - Geology, Ecology, and Landscapes 2(4): 229-239.

[25] Raja, B. (2017): Some properties of hypergeometric functions for Sakaguchi type functions. - Revista de la Facultad de Agronomia de la Universidad del Zulia 34(4).

[26] Rajput, K., Gupta, A., Arus, H. (2019): Re-cycle of e-waste in concrete by partial replacement of coarse aggregate. - Engineering Heritage Journal. DOI: 10.26480/gwk.01.2019.05.08.

[27] Reddy, S. S., Momoh, J. A. (2016): Minimum emissions optimal power flow in windthermal power system using opposition based bacterial dynamics algorithm. - 2016 Power and Energy Society General Meeting, IEEE. DOI: 10.1109/PESGM.2016.7741635.

[28] Rojamary, T., Uma, K. P. (2017): A stochastic model for the cost analysis of a system with two components for the loss of manpower threshold. - Revista de la Facultad de Agronomía 34(2). 
[29] Salem, R., Bahadorijahromi, A., Mylona, A. (2018): Comparison and evaluation of the potential energy, carbon emissions, and financial impacts from the incorporation of CHP and CCHP systems in existing UK hotel buildings. - Energies 11(5): 1219.

[30] Shrestha, A., Baral, S. (2018): Socioeconomic factors affecting awareness and adaption of climate change: a case study of Banke District Nepal. - Earth Sciences Malaysia 2(2): 20-24.

[31] Sufiyan, I., Zakariya, R., Yaacob, R. (2018): Delineation of flood risk zones and 3D modeling In Terengganu River catchment using GIS and SWAT. - Environment \& Ecosystem Science 2(2): 01-05.

[32] Taylor, J. B. (2009): The financial crisis and the policy responses: an empirical analysis of what went wrong. - NBER Working Papers 21(2-3): 341-364.

[33] Valiani, S., Tahouni, N., Panjeshahi, M. H. (2016): Optimization of pre-combustion capture for thermal power plants using pinch analysis. - Energy 119: 950-960.

[34] Velea, S., Dragos, N., Serban, S. (2009): Biological sequestration of carbon dioxide from thermal power plant emissions, by absorption in microalgal culture media. - Romanian Biotechnological Letters 14(4): 4485-4500. 